in fertilized eggs from one subspecies of mouse with those from another subspecies.

Embryos containing nuclear DNA from Mus mus domesticus and mitochondrial DNA (mtDNA) from Mus mus musculus produced healthy female progeny and males with reduced fertility. However, most of the embryos containing nuclear DNA from M. m. musculus and mtDNA from $M . m$. domesticus were aborted or stillborn.

Should mitochondrialreplacement therapy reach the clinic, the authors recommend selecting donors with similar mtDNA to recipients.

Cell Metab. http://doi.org/bmn5 (2016)

\section{MATERIALS \\ Shape-shifters made with a snap}

Materials that include a modular system of hinges have been used to build shapeshifting structures.

Current methods can make reconfigurable structures with only a limited number of stable forms. To make such materials more versatile, Lorenzo Valdevit of the University of California, Irvine, and his colleagues created a triangular Teflon structure several centimetres across, with hinges that allow it to snap into an open or closed configuration. By linking these subunits together, the team built 3D structures with multiple stable positions (pictured).

The approach could be used with a wide range of materials to make tools that have different forms and functions, the authors say.

Adv. Mater. http://doi.org/f3qmr2 (2016)

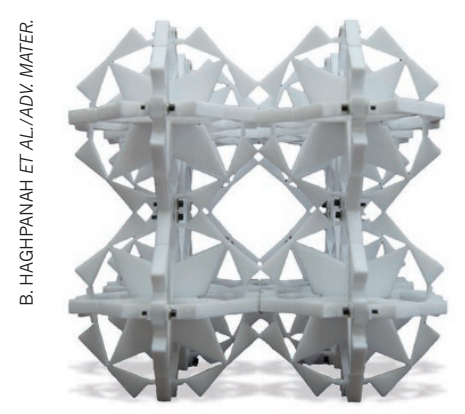

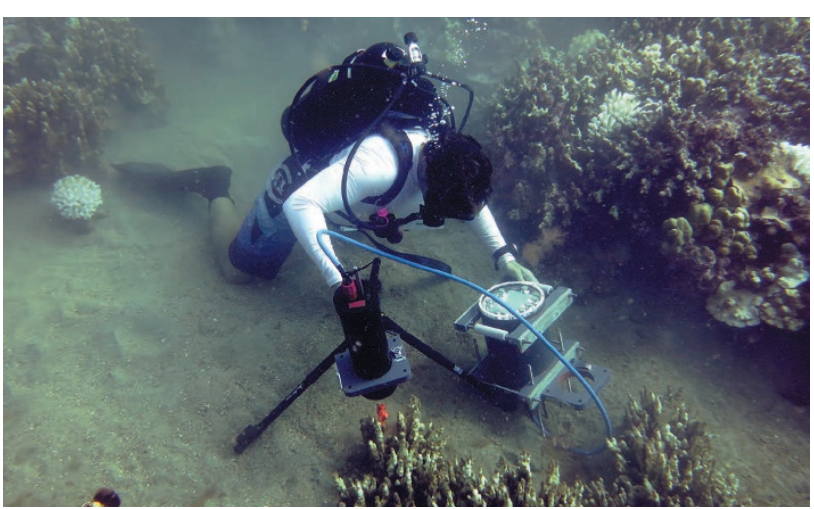

\section{OCEAN SCIENCE}

\section{Microscope can} see under the sea

An underwater microscope allows researchers to capture behaviours of corals and other marine organisms in their native habitats.

Andrew Mullen at the Scripps Institution of Oceanography in La Jolla, California, and his colleagues designed a system (pictured left) that divers can use to take almost micrometre-resolution images (Stylophora coral pictured right) at depths of up to 30 metres. It lets marine biologists observe biological processes on the sea floor that cannot be easily replicated in a lab.

The authors used their instrument to study millimetre-sized coral polyps off the coast of Maui, Hawaii, in 2015, during the first mass coral-bleaching event recorded for the main Hawaiian islands. They found that algae colonized bleaching corals in specific patterns. Near Eilat in Israel, they discovered that coral polyps connect to each other through their openings, probably to share chemicals. Nature Commun. 7, 12093 (2016)

\section{Chlorine atom arrays store data}

A device that uses arrangements of atoms to encode and store information has orders of magnitude more capacity than current hard drives.
Sander Otte at Delft University of Technology in the Netherlands and his colleagues assembled arrays of chlorine atoms on a nanometresized copper surface. They used a scanning tunnelling microscope to manipulate the atoms and vacant spaces on the surface, creating many different arrangements that encode information. The researchers used these arrays to build a 1-kilobyte rewritable data-storage device with an information density as high as 78 terabits per square centimetre.

If the device were scaled up, it could store the entire US Library of Congress in a cube just 100 micrometres wide, according to the authors. Nature Nanotech. http://dx.doi. org/10.1038/nnano.2016.131 (2016)

\section{BEHAVIOURAL ECOLOGY}

\section{Bees like their pollen sweet}

Bees can taste the pollen they collect, and favour the sweet kind.

Felicity Muth and her colleagues at the University of Nevada in Reno offered bumblebees (Bombus impatiens) an artificial flower containing one of three types of pollen - sweet, bitter or unflavoured. Bees presented with the sweet flower spent longer collecting pollen than did those offered the other types. When the bees were presented with two more flowers, one of which was the same colour as the first, few bees opted to change colour

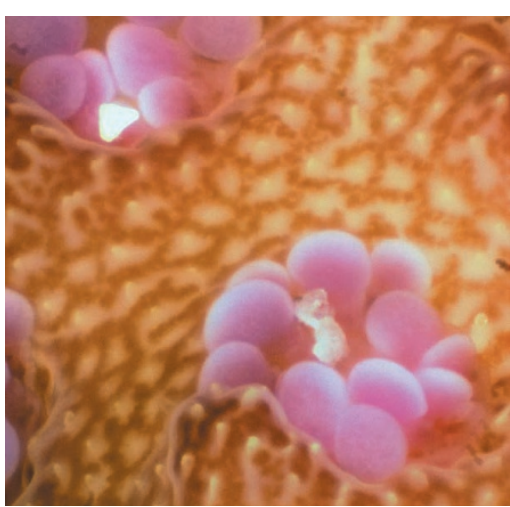

if their first flower had been sweet or unflavoured.

Many plants rely on bees for widespread pollination, so plants may have evolved pollen just sweet enough to keep bees coming back for more, but not so sweet that one bee takes it all, the authors say. Biol. Lett. 12, 20160356 (2016)

\section{NEURODEGENERATION}

\section{ALS gene linked to autoimmunity}

A gene that is often mutated in people with a neurodegenerative disease may help to keep immune responses in check.

Mutations in the C9ORF72 gene are commonly found in people with motor neuron disease, also known as amyotrophic lateral sclerosis (ALS), as well as in people with a form of dementia. To determine the function of the C9ORF72 protein, Kevin Eggan at Harvard University in Cambridge, Massachusetts, and his colleagues introduced mutations that diminished or eliminated the function of the equivalent protein in mice. The mutant mice had autoimmune disease, over-produced inflammatory molecules and died prematurely.

The authors conclude that C9ORF72 has an important role in controlling inflammation and autoimmunity.

Sci. Transl. Med. 8, 347ra93 (2016)

\section{ONATURE.COM}

For the latest research published by Naturevisit:

www.nature.com/latestresearch 